\title{
Why we still love Lucy
}

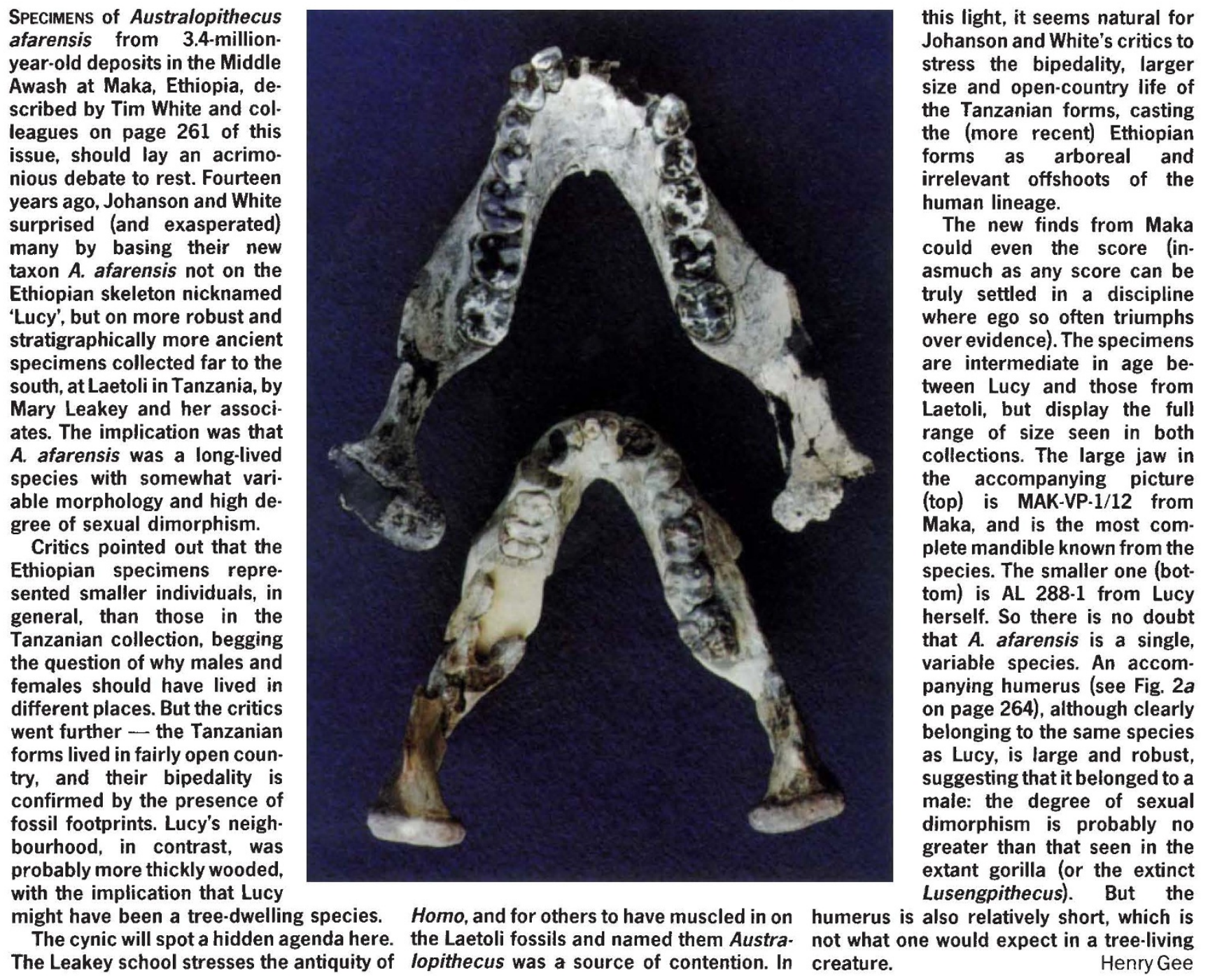

photoreduction is coupled to enzymatically catalysed reduction of nitrate to nitrite. The coupling is neatly achieved by covalent bonding of the enzyme nitrate reductase to the polyimine polymer. The latter serves to transport electrons between the $\mathrm{TiO}_{2}$ particle and the enzyme. Electron flow occurs in cascade fashion: the conduction-band electrons reduce the viologen which in turn reduces the nitrate reductase. Two electrons are pooled by the catalytically active group of the enzyme before they are passed to the nitrate substrate to yield nitrite as a final product.

The concept is not new; electroactive polymers of similar type have been applied previously ${ }^{3}$ to ensure electronic charge transfer between macroscopic electrodes and enzymes. But the results of Willner and colleagues open the way to extend this type of redox 'wiring' to colloidal assemblies of semiconductors and enzymes.

Apart from the reduction of nitrate, photobiocatalytic semiconductor nanocrystals may be applicable to other multielectron transfer reactions that require the intervention of natural enzymes or artificial redox catalysts. An example is the reduction of carbon dioxide. The efficiency of these photocatalytic reactions is often poor, and using redox-wired semiconductor/enzyme assemblies may well lead to improvement of the quantum yields. There are strong hopes of generating fuels such as methanol or fertilizers such as ammonia in this way using sunlight.

Instead of dispersing the colloidal semiconductor particles in solution, one can deposit them as a layer on a conducting glass support. Such nanocrystalline films exhibit some extraordinary properties. For example, colloidal $\mathrm{TiO}_{2}$ films whose surfaces were treated with a chargetransfer sensitizer are extremely efficient at photovoltaic conversion of solar energy ${ }^{4}$. Another useful feature is that the Fermi level within the particles can be potentiostatically controlled by incorporating the supported film as the working electrode in a conventional threeelectrode electrochemical cell. This opens up the prospect of using assemblies of the type reported by Willner and colleagues as catalytic enzyme electrodes. Multielectron reduction processes could then be accomplished in the dark, the particle layer being used as a cathode. And indeed, studies in progress at University College Dublin (D. Fitzmaurice, personal communication), using molecular triads (which are composed of three redox-active molecules, with a gradient in redox potential from the first to the third) bound to the surface of nanocrystalline $\mathrm{TiO}_{2}$ films, confirm that vectorial electron flow occurs and that efficient charge separation can be obtained with such systems.

M. Grätzel is at the Institut de Chimie Physique, Ecole Polytechnique Fédéral de Lausanne, 1015 Lausanne, Switzerland.

\footnotetext{
Grätzel. M. Heterogeneous Photochemical Electron Transfer (CRC, Boca Raton, 1989).

2. Wiilner, I., Eichen, Y., Frank, A. J. \& Fox, M. A. J. phys. Chem. 97, 7264-7267 (1993)

3. Heller, A. Accts chem. Res. 23, 128 (1990).

4. O'Regan, B. \& Grätzel, M. Nature 353, 257-260 (1991).
} 